\title{
Entendimento do Tribunal de Justiça do Pará sobre o erro médico na esfera penal
}

\author{
Understanding of the Court of Justice of \\ Pará on medical error in the criminal sphere
}

Isabel de Fátima Alvim Braga', Laila Zelkcovicz Ertler², Helena Beatriz da Rocha Garbin ${ }^{3}$

${ }^{1}$ Medicina do Trabalho, Fundação Oswaldo Cruz (FIOCRUZ) - Rio de Janeiro (RJ), Brasil.

${ }^{2}$ Medicina Interna, Universidade Federal do Rio de Janeiro (UFRJ) - Rio de Janeiro (RJ), Brasil.

${ }^{3}$ Departamento de Saúde Pública, FIOCRUZ - Rio de Janeiro (RJ), Brasil.

DOI: http://dx.doi.org/10.7322/abcshs.v42i3.987

\section{RESUMO}

Introdução: O processo por erro médico costuma ter impacto profundo tanto navida profissional como na vida pessoal do médico. Entretanto, como a judicialização da medicina é recente, carece de estudos com análise dos fatos a partir da dupla perspectiva da Medicina e do Direito. Objetivo: Analisar os processos da esfera penal do Tribunal de Justiça do Pará. Métodos: Foi realizada uma pesquisa por palavra-chave no site do Tribunal de Justiça do Estado do Pará (TJPA) com o termo de pesquisa: "erro médico". Resultados: Foram encontrados 42 julgados jurisprudenciais. Desses, 24 foram excluídos, pois: 4 eram repetições; 19 eram crimes não cometidos por médicos e 1 por tratar de difamação. Ocorreu uma prescrição e três processos ainda não haviam sido julgados na primeira instância. Dos 14 processos julgados, houve 6 condenações e 8 absolvições. A distribuição por especialidades se deu da seguinte maneira: 8 na ginecologia-obstetrícia (GO); 4 na emergência clínica; 2 na cirurgia geral; 1 em anestesiologia/ cirurgia plástica; 1 em oftalmologia; 1 em ortopedia; e 1 em radiologia. Conclusão: Os casos de acusação de supostos erros cometidos por médicos no exercício de suas especialidades ainda são raros no panorama geral do Pará. As especialidades ligadas à cirurgia e às situações de emergência, principalmente $\mathrm{GO}$, foram as principais envolvidas nesse tipo de processo.

Palavras-chave: direito penal; responsabilidade técnica; medicina defensiva; erros médicos.

\begin{abstract}
Introduction: The medical error process usually has a profound impact on both professional and personal life of the doctor. However, since the judicialization of medicine is recent, there is a need to study the facts from the dual perspective of medicine and law. Objective: To analyze the criminal proceedings of the Pará Court of Justice. Methods: A keyword search was performed on the website of the Court of Justice of the State of Pará (TJPA) with the search term: "medical error". Results: Forty-two sentences were found. Of these, 24 were excluded because: four were repetitions; 19 were crimes not committed by doctors and one was defamation. In addition, one prescription occurred and three cases had not yet been tried at first instance. Of the 14 lawsuits judged, there were six convictions and eight acquittals. The distribution by specialties was as follows: eight cases in obstetrics/gynechology (Ob-Gyn); four in clinica emergency; two in general surgery; one in anesthesiology/ plastic surgery; one in ophthalmology; one in orthopedics; and one in radiology. Conclusion: The cases of accusation of alleged errors committed by doctors in the exercise of their specialties are still rare in the state of Pará. Specialties related to surgery and emergency situations, especially Ob-Gyn, seem to be the main ones involved in this type of process.
\end{abstract}

Keywords: criminal law; technical responsibility; defensive medicine; medical errors.

Recebido em: 18/06/2017

Revisado em: 22/08/2017

Aprovado em: 18/10/2017

Autor para correspondência: Isabel de Fátima Alvim Braga - Fundação Oswaldo Cruz - Avenida Brasil, Estrada de Manguinhos, 4.365 - Manguinhos CEP: 21040-900 - Rio de Janeiro (RJ), Brasil. E-mail: isabelbragamed@gmail.com

Conflito de interesses: nada a declarar. 


\section{INTRODUÇÃO}

Um processo sobre erro médico costuma ter impacto profundo e devastador na vida profissional e pessoal de um esculápio, com consequências sobre seu estilo de vida, sua família, seus colegas e seus pacientes ${ }^{1}$.

A medicina sempre foi considerada uma das mais nobres ofícios do mundo. Não obstante, recentemente, a relação paciente-médico diminuiu seu caráter de confiança na pessoalidade e tornou-se mais formal e estruturada, não havendo mais a aura de infalibilidade e inquestionabilidade ao profissional esculápio de outrora ${ }^{2}$. Existe, assim, hodiernamente, uma crença de que todo resultado indesejado, no exercício da medicina, deva ser de responsabilidade do médico ${ }^{3}$.

A judicialização da medicina vem gerando a necessidade de análise dos fatos a partir da dupla perspectiva da Medicina e do Direito $^{4}$. No entanto, a lei, como a medicina, é uma ciência inexata ${ }^{2}$, o que gera questões idiossincráticas em cada decisão processual.

O reconhecimento do problema citado no parágrafo anterior vem fazendo surgir o entendimento de que publicações envolvendo questões jurídicas mereceriam espaço em revistas científicas especializadas na área médica, com o intuito de promover a discussão sobre essa temática ${ }^{5}$.

Com o intuito de colaborar para a discussão desse tipo de informação, foi realizado um levantamento de dados sobre a temática dos processos sobre erro médico dessa esfera penal, objetivando: estabelecer a frequência de processos penais; verificar a frequência de condenações em primeira instância; verificar os crimes pelos quais os médicos são acusados; e avaliar a distribuição temporal das demandas.

\section{MÉTODOS}

Foi realizada uma pesquisa por palavra-chave no site do Tribunal de Justiça do Estado do Pará (TJPA) ${ }^{6}$ com o seguinte termo de pesquisa: "erro médico". Não foi determinado período temporal. Em uma primeira seleção, foram encontrados 356 julgados. Posteriormente, foi selecionado o campo sessão criminal, restando 42 julgados, porém, somente os processos em que o médico figurava no polo passivo (réu) foram analisados.

Os dados obtidos na pesquisa foram tratados com o uso do aplicativo Excel 2007 e as variáveis analisadas foram as seguintes:

1. Tipo penal (crime);

2. Especialidade em que estava $(\mathrm{m})$ atuando o(s) réu(s);

3. Condenação em primeira instância (sim ou não);

4. Ano da distribuição da ação;

5. Ano do julgamento do recurso encontrado;

6. Reforma da decisão em segunda instância (sim ou não) para os recursos que tratavam de apelação.

Os dados utilizados foram todos de âmbito público e estavam disponíveis na internet. As autoras declaram não haver conflito de interesses. O presente projeto foi aprovado em Comitê de Ética em Pesquisa com o número CAAE 68109017.2.0000.5248.

\section{RESULTADOS}

Foram encontrados 42 julgados jurisprudenciais. Desses, 24 foram excluídos pelos seguintes motivos: 4 por se tratarem de repetições; 1 por se tratar de crime de difamação sem relação com erro médico; e 19 por se tratarem de crimes não cometidos por médicos.

A distribuição temporal dos 18 processos restantes se deu da seguinte maneira, para ano de distribuição: 1 em 2000; 1 em 2001; 1 em 2002; nenhum em 2004; 2 em 2005; 2 em 2006; 2 em 2007; 1 em 2008; 1 em 2009; 1 em 2010; 2 em 2011;1 em 2013; 2 em 2016; e 1 em 2017 (Figura 1). Já a distribuição dos julgamentos (recursos) encontrados em segunda instância se deu da seguinte maneira: 1 em 2008; 2 em 2009; 1 em 2010; 1 em 2011; 2 em 2012; 5 em 2015; 1 em 2016; e 5 em 2017 (Figura 1). A diferença gráfica entre os anos de julgamento e os de distribuição (início) da ação está disposta na Figura 1, sendo a média temporal entre o ano de distribuição da ação e o tempo até o recurso de 5,389 anos. Foram encontrados $12(66,67 \%)$ casos de homicídio e $6(33,3 \%)$ de lesão corporal.

No que concerne à absolvição ou à condenação, ocorreu 1 prescrição $(5,56 \%)$ e $3(16,67 \%)$ processos ainda não haviam sido julgados na primeira instância, sendo os recursos relativos a atividades judiciais anteriores à apreciação do juiz pela questão do crime per si. Dos 14 (77,78\%) processos em que houve julgamento do mérito, isto é, o juiz decidiu, houve 6 condenações e 8 absolvições.

Dentre os recursos, dez eram apelações. No que concerne à reforma da decisão dentre os recursos que eram apelações, dos cinco absolvidos, nenhuma reforma em segunda instância ocorreu. Dentre as cinco condenações em primeira instância que foram alvo de apelação, quatro foram reformadas.

A distribuição entre os procedimentos clínicos e cirúrgicos se deu da seguinte maneira: 15 (83,33\%) cirúrgicos e 3 (16,67\%) clínicos (Figura 2).

A distribuição por especialidades foi a seguinte: 8 na ginecologia-obstetrícia (GO); 4 na emergência clínica; 2 na cirurgia geral; 1 em anestesiologia/cirurgia plástica; 1 em oftalmologia; 1 em ortopedia; 1 em radiologia (Figura 3).

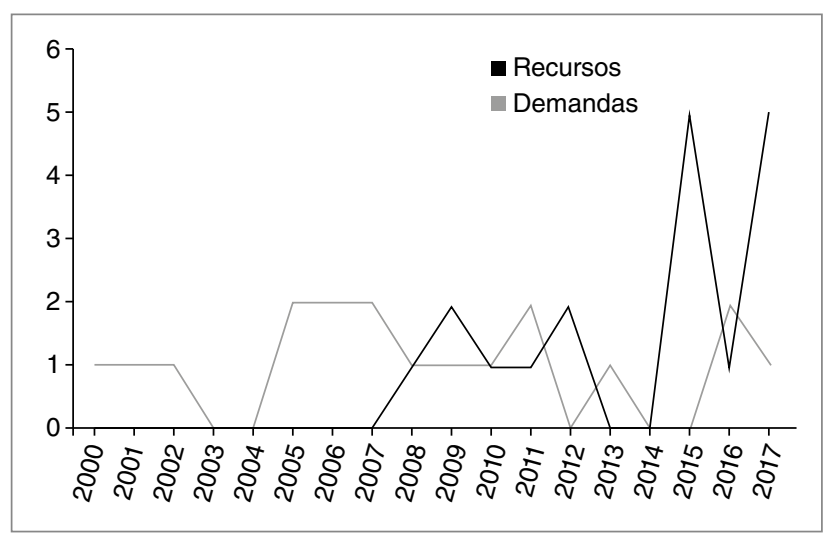

Figura 1: Distribuição temporal das demandas e recursos 
Os procedimentos encontrados foram: cirurgia bariátrica complicada com fístula (1); cirurgia plástica (lipoaspiração) eletiva realizada em paciente com anemia que foi a óbito (1); paciente que chegou ao hospital já em parada cardiorrespiratória e o médico foi acusado de não ter feito o atendimento adequado e ter sido negligente (1); cirurgia ortopédica de coluna que deixou como sequelas dores (1); cirurgia para hemorragia subaracnoidea que não evitou o óbito da paciente (1); cirurgia para correção de catarata em que ocorreu descolamento de retina (1); colecistectomia em que foi esquecida uma gaze na região abdominal do paciente, levando à sepse (1); pneumonia não diagnosticada (1); tratamento não cirúrgico de colelitíase que evoluiu com colangite e óbito por sepse (1); exame ultrassonográfico que não evidenciou

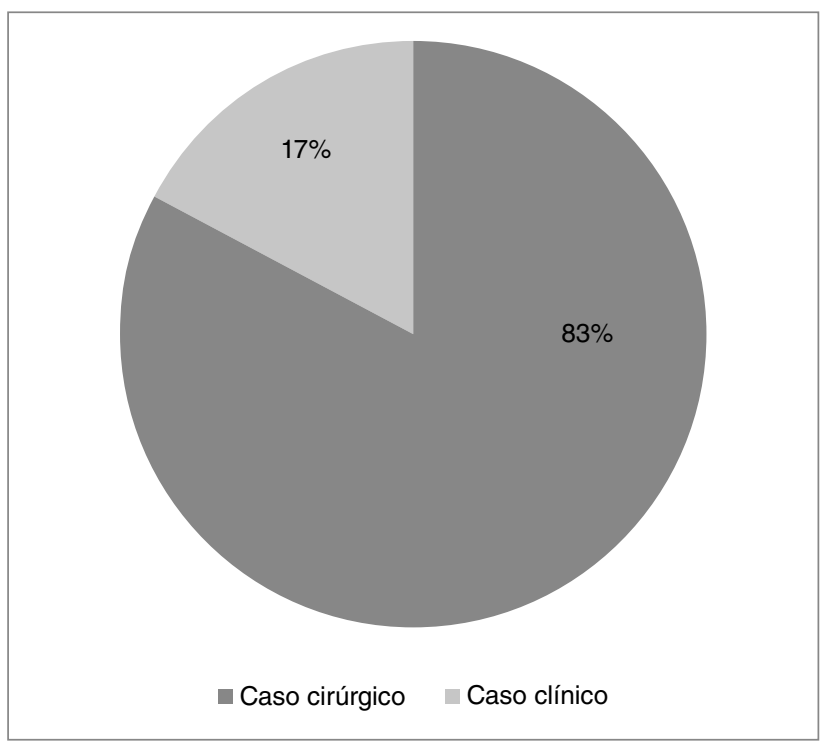

Figura 2: Distribuição dos processos por tipo de procedimento: clínico ou cirúrgico

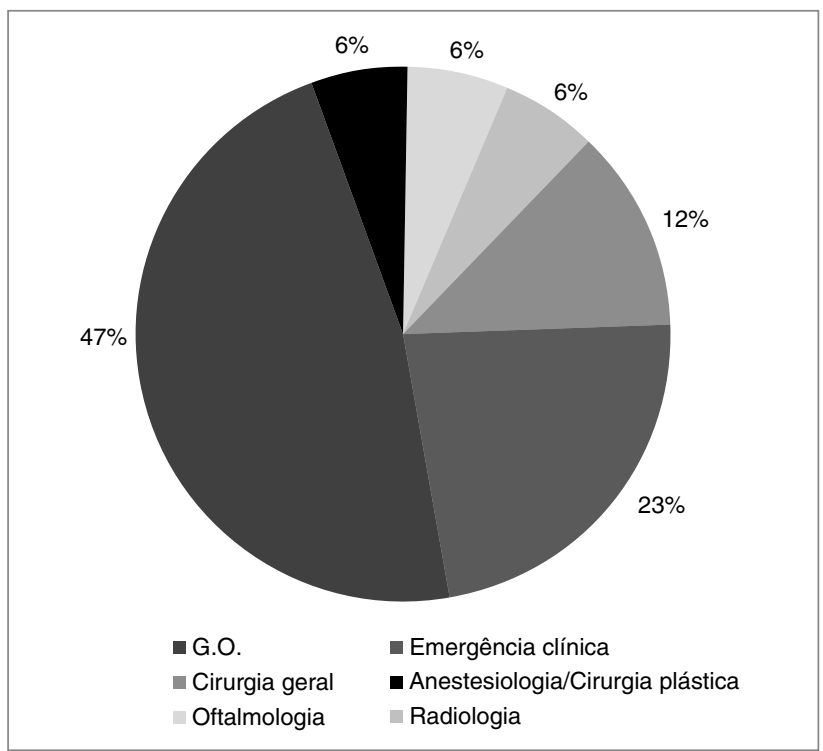

Figura 3: Distribuição dos processos por especialidade médica amniorrexe prematura (1); histerectomia em que supostamente houve erro na anestesia, causando o enfraquecimento da musculatura do membro inferior direito (1); curetagem com perfuração intestinal e que deixou restos ovulares (1); desfechos infelizes em partos (6) dos quais: 1 parto por rotura prematura de membrana ovular cujo concepto evoluiu com sepse; 1 hemorragia após cesariana; 1 parto normal convertido em cesariana que gerou lesão neurológica no feto; 1 parto em paciente com miastenia gravis complicado com morte fetal e lesão perineal; 1 parto cesariana com laqueadura tubária complicado com perfuração de íleo terminal; 1 parto normal com morte neonatal por choque séptico.

\section{DISCUSSÃo}

O Pará é o único Estado da região norte que tem um Tribunal de Justiça de médio porte, pois a região possui predominantemente tribunais de pequeno porte. Esse Estado conta com 111 comarcas e 308 varas ou juizados, o que o coloca em uma posição privilegiada, sendo considerado com excelente proporção entre magistrados e população ${ }^{7}$. Em razão da importância desse tribunal para a região norte, ele foi eleito para ser analisado no presente trabalho.

O tempo médio de tramitação dos processos baixados nas varas para a execução é de 5,5 anos ${ }^{7}$. Esse dado é assaz similar ao encontrado em nosso estudo, em que a média temporal entre a distribuição pela primeira instância e o tempo de recurso foi de 5,39 anos.

A Figura 1 apresenta a demora no julgamento dos recursos e quanto o processo decisório é lento. Com o objetivo de avaliar a diferença temporal entre o momento que o processo ingressou no sistema e o qual foi analisado pela segunda instância, a distribuição temporal dos processos foi analisada de duas maneiras: por meio do seu ano de distribuição e pelo ano de julgamento, conforme disposto na Figura 1. Observa-se evidente e significante atraso no julgamento de recursos em relação ao início do caminho da ação.

A quantidade de novos casos criminais em primeira instância no ano de 2016, no Tribunal de Justiça do Estado do Pará (TJ-PA), segundo dados do Conselho Nacional de Justiça (CNJ) de 2016, foi substancialmente alta: 54.579 . Isso mostra como os processos pelo chamado "erro médico" representam um quantitativo mínimo das ações.

Nesse mesmo ano ainda existiam 202.789 casos pendentes de julgamento ${ }^{7}$. Em razão desse congestionamento e de nossa casuística incluir apenas os processos que passaram de alguma maneira pela segunda instância, há um viés de seleção no presente estudo. Sendo assim, alguns processos podem ter sido perdidos pela técnica de pesquisa, em razão de estarem em fase muito inicial e ainda sem recursos ou decisões ou terem tido algum tipo de acordo, trancamento ou transação penal na primeira instância, ou ainda por terem sido classificados no sistema de forma equivocada, como o ocorrido com alguns dos processos que foram descartados da análise. 
Sobre a palavra-chave "erro médico", embora seja um termo de indexação frequentemente utilizado no judiciário, é uma variável dependente de quem coloca os processos no sistema. Em razão disso, é possível que tenha havido perda de dados que o método não permite mensurar.

Em nosso estudo predominaram nos processos os casos de homicídio. Um levantamento de dados sobre a temática dos processos da esfera penal no Tribunal de Justiça do Rio Grande do Sul encontrou somente processos sobre homicídio culposo, com taxas de absolvição similares à do presente estudo (61,5\% dos julgados). Estudo realizado na Região Nordeste, de cunho retrospectivo e realizado pelo preenchimento de fichas do arquivo da Promotoria de Justiça Especializada na Defesa da Saúde ${ }^{8}$, diferenciou-se do presente pela predominância das taxas de lesão corporal culposa $(51,1 \%)$ em relação ao homicídio culposo (37,8\%). Não foram encontrados casos de processo envolvendo o crime de lesão corporal seguida de morte. A pena varia bastante entre esses tipos penais. Para o homicídio culposo, previsto no artigo 121 do Código Penal (CP), a pena é de detenção de um a três anos, podendo ser aumentada em um terço caso seja resultante de inobservância de regra técnica profissional (como ocorre quando a condenação é por erro médico). Não obstante, a pena para lesão corporal prevista no Código 129 do CP possui pena base de detenção de três meses a um ano. Caso seja grave (quando gera perigo de vida; incapacidade por mais de 30 dias para ocupação habitual; aceleração de parto; ou debilidade permanente de membro, sentido ou função), a pena é de 1 a 5 anos; e para a gravíssima (quando gera aborto; enfermidade incurável; deformidade permanente; ou inutilização de membro, sentido ou função), de 2 a 8 anos. A lesão corporal na modalidade culposa possui como pena dois meses a um ano, podendo ser aumentada em um terço caso ocorram os mesmos motivos para aumento de pena do homicídio culposo.

Nosso estudo encontrou uma maior prevalência de casos em especialidades cirúrgicas em relação à clínica. Essa correlação também foi encontrada em estudo realizado no Conselho Regional de Medicina (CRM) da Bahia ${ }^{9}$ e no Tribunal de Justiça do Rio Grande do Sul ${ }^{10}$. A maioria esmagadora das situações que ensejaram ações penais estava correlacionada a situações de urgência/emergência e GO. Possivelmente, isso é decorrente do sucesso dessa especialidade estar conexo a uma boa relação médico-paciente, cuja confiabilidade parece estar se esvaindo em razão do furor midiático nas questões do parto.

O destaque dado à obstetrícia nos processos médicos não parece ser exclusivo dos tribunais paraenses, sendo esse dado corroborado pelos estudos de Udelsmann, no CRM de São Paulo ${ }^{11}$, e Koeche, no CRM de Santa Catarina ${ }^{12}$.

$\mathrm{Da}$ mesma forma, as situações de emergência se destacaram como originadoras de processos penais. O tempo limitado, a imprevisibilidade e a falta de continuidade da relação médico-paciente são as possíveis geratrizes do alto risco jurídico dessa área médica ${ }^{13}$. Estudo realizado no Tribunal de Justiça do Rio Grande do Sul (TJ-RS) apontou que as situações de urgência e emergência eram preditoras para a judicialização dos casos naquele estado?.

Dois casos envolveram cirurgia bariátrica, sendo um de forma direta e outro indiretaente, com uma cirurgia plástica realizada em paciente com anemia após esta.

Em 2005, publicação de Eagan já apontava para o fato de que o crescimento esperado do número de operações desse tipo no futuro aumentaria os casos judiciais e apontou para a necessidade da gestão de riscos nesses pacientes ${ }^{14}$. Nos Estados Unidos, a cirurgia bariátrica foi classificada como de alto risco pela indústria de negligência médica. Estudo realizado com cirurgiões americanos evidenciou que o risco de ser processado realizando uma cirurgia desse tipo era de 1,6/1.000 casos, com prêmio monetário indenizatório médio de 88.667 dólares americanos ${ }^{15}$.

Sobre o caso envolvendo o esquecimento de gaze no abdome em uma cirurgia de colecistectomia, salientamos nossa dificuldade em encontrar estudos comparativos envolvendo esse tipo de procedimento nos tribunais de justiça. Sendo assim, utilizamos para fins de análise de risco estudo conduzido por Ishak et al. no Serviço de Cirurgia Geral e do Aparelho Digestivo do Hospital Universitário João de Barros Barreto, que avaliou aspectos epidemiológicos de pacientes com lesões iatrogênicas das vias e encontrou 25 casos desse tipo de lesão, com $88 \%$ delas tendo decorrido de colecistectomias ${ }^{16}$.

A maioria dos processos teve o médico absolvido, mas com taxas inferiores a outros estudos, como observado em pesquisa sobre responsabilidade civil no Tribunal de Justiça de São Paulo (TJ/SP $)^{17}$. É possível inferir que processos de menor gravidade estejam no âmbito cível, e não penal, podendo justificar essa diferença numérica. Essa mesma diferença em taxas de condenação ocorre quando o presente estudo é comparado a outro na mesma localidade em processos administrativos. Estudo com sindicâncias e processos ético-profissionais no Conselho Regional paraense com dados de 2005 a 2007 mostra taxas de absolvição de $40 \%$ (8) do total em 2005, passando a $52,3 \%$ (23) em 2006 e terminando em 65,2\% (30) em 2007. Tal resultado se assemelha à nossa taxa de absolvição (57\%), se considerarmos apenas os julgados com decisão sobre condenação ou absolvição, ou seja, sobre o mérito, em primeira instân$\mathrm{cia}^{18}$. Destacamos que, apesar de poucos dados relativos às reformas das decisões em razão do delongamento do judiciário, houve reforma em segunda instância da maioria das decisões que condenou o médico em primeira instância. Não obstante, não dispusemos de dados comparativos para análise desse fato.

Em conclusão, os casos de crimes supostamente cometidos por médicos no exercício de suas especialidades ainda são raros no panorama geral do Estado do Pará, mas com taxas de condenação em primeira instância bastante superiores àquelas dos julgamentos cíveis de outros estudos utilizados para comparação. 


\section{REFERÊNCIAS}

1. Lavery JP. The physician's reaction to a malpractice suit. Obstet Gynecol. 1988;71(1):138-41.

2. Raveesh BN, Nayak RB, Kumbar SF. Preventing medicallegal issues in clinical practice. Ann Indian Acad Neurol. 2016 O;19(Suppl 1):S15-20. http://dx.doi.org/10.4103/0972-2327.192886

3. Couto Filho AF, Pereira AP. A improcedência no suposto erro médico. Rio de Janeiro: Lumen Júris; 1999.

4. Robles-Elías FJ, Peña-Nina D, Díaz-Barriga E, Robles-Morales R. Decriminalize medical procedures? A first approach from a dual perspective: medicine and law. Ginecol Obstet Mex. 2014;82(12):828-38

5. Nagpal N. Do legal issues deserve space in specialty medical journals? J Assoc Physicians India. 2016;64(2):86-7.

6. Tribunal de Justiça do Estado do Pará. Pesquisa de jurisprudência. Disponivel em: http://www.tjpa.jus.br/PortalExterno/institucional/ Acordaos-e-Jurisprudencia/168242-Pesquisa-de-Jurisprudencia. xhtml. Acesso em: 21 jun. 2017.

7. Conselho Nacional de Justiça. Justiça em números 2016: anobase 2015. Brasília: Poder Judiciário; 2016.

8. Maia DB, Figueiredo Neto JA, Abreu SB, Silva DSM, Brito LMO. Perfil dos processos por erro médico em São Luís. Rev Pesq Saúde. 2011;12(2):18-22.

9. Bitencourt AGV, Neves NMBC, Neves FBCS, Brasil ISPS, Santos LSC. Análise dos erros médicos em processos ético-profissionais: implicações na educação médica. Rev Bras Educ Med. 2007;31(3):223-8.

http://dx.doi.org/10.1590/S0100-55022007000300004
10. Ertler LZ, Braga IFA, Pereira RBM, Aquino RM, Silva BAF. Erro médico na esfera penal no Tribunal de Justiça do Rio Grande do Sul. Rev AMRIGS. 2017. No prelo.

11. Udelsmann A. Responsabilidade civil, penal e ética dos médicos Rev Assoc Med Bras. 2002;48(2):172-82. http://dx.doi.org/10.1590/S0104-42302002000200039

12. Koeche LG, Cenci I, Bortoluzzi MC, Bonamigo EL. Prevalência de erro médico entre as especialidades médicas nos processos julgados pelo Conselho Regional de Medicina do Estado de Santa Catarina. Arq Catarin Med. 2013;42(4):45-53.

13. Cohen D, Chan SB, Dorfman M. Malpractice claims on emergency physicians: time and money. J Emerg Med. 2012;42(1):22-7. http://dx.doi.org/10.1016/j.jemermed.2008.06.014

14. Eagan MC. Bariatric surgery: malpractice risks and risk management guidelines. Am Surg. 2005;71(5):369-75.

15. Casey BE, Civello Jr. KC, Martin LF, O'Leary JP. The medical malpractice risk associated with bariatric surgery. Obes Surg. 1999;9(5):420-5 http://dx.doi.org/10.1381/096089299765552684

16. Ishak G, Feitosa Junior NQ, Meireles WM, Magalhães TC, Costa CS, Carvalho RDG. Aspectos epidemiológicos de pacientes com lesões iatrogênicas das vias biliares. Rev Para Med. 2015;29(2):33-8.

17. Braga IFA, Vieira KO, Martins TGDS. Civil liability of the ophthalmologist in the São Paulo Court of Appeals. Einstein. 2017;15(1):40-4.

http://dx.doi.org/10.1590/S1679-45082017AO3781

18. Silva JAC, Brito MVH, Oliveira AJB, Brito NB, Gonçalves RS, Fonseca SNS. Sindicâncias e processos ético-profissionais no Conselho Regional de Medicina do Pará: evolução processual no período de 2005 a 2007. Rev Bras Clin Med. 2010;8(1):20-4. 